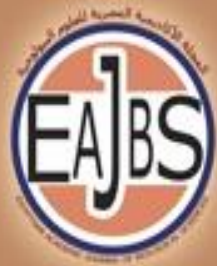

EGYPTIAN ACADEMIC JOURNAL OF
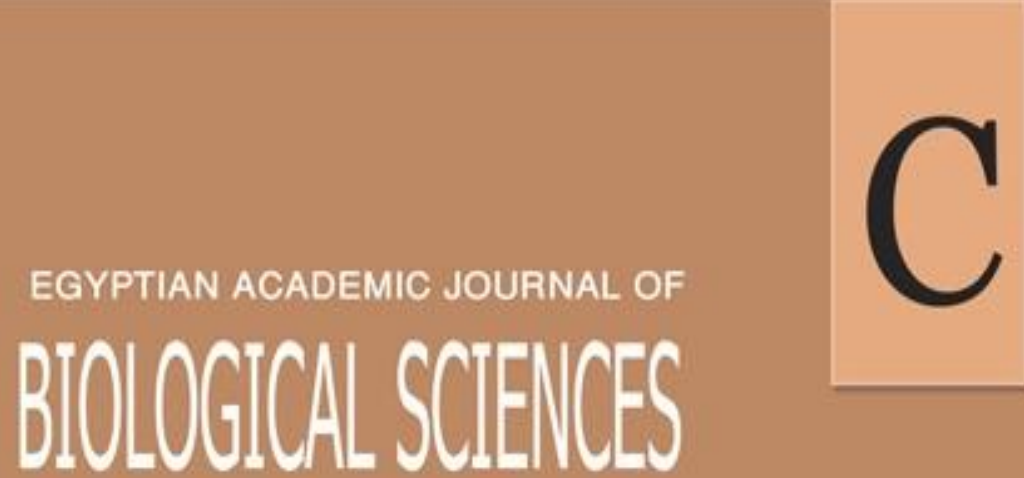

PHYSIOLOGY \& MOLECULARBIOLOGY
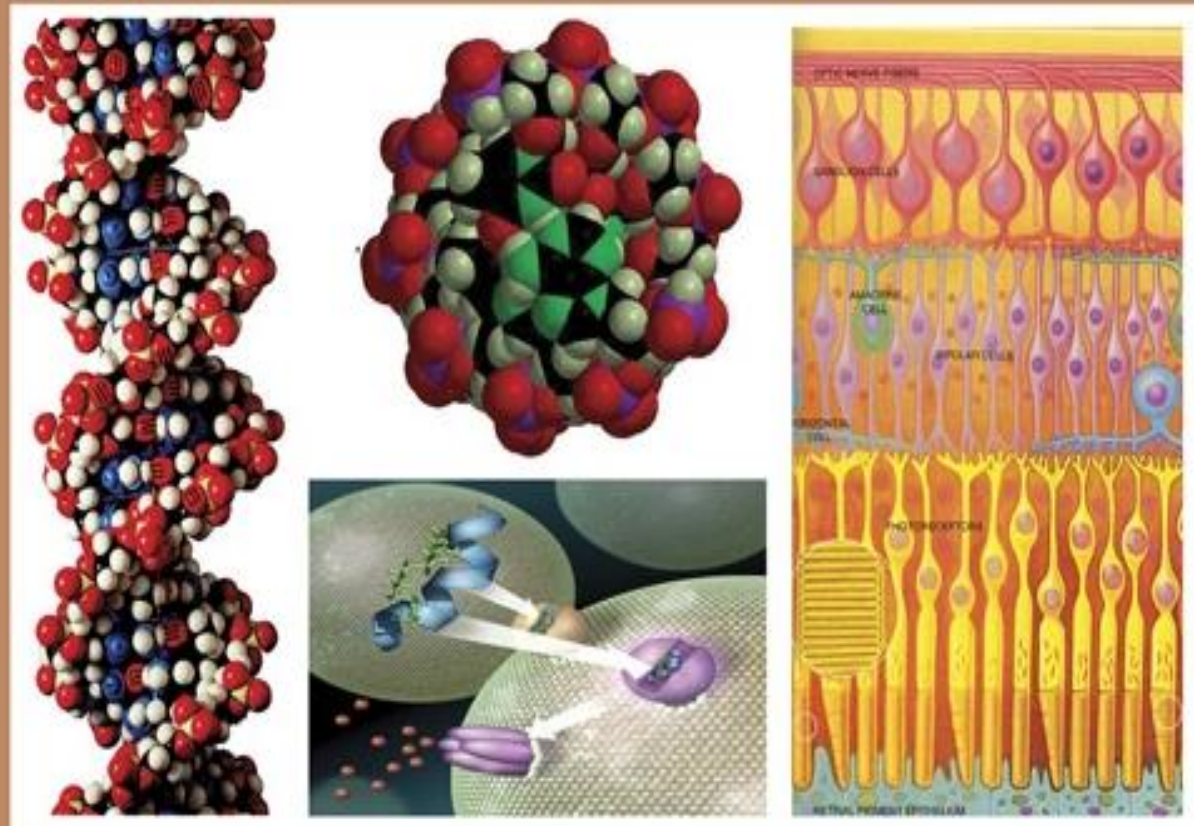

ISSN

2090-0767

WWW.EAJBS.EG.NET

Vol. 14 No. 1 (2022) 
Egypt. Acad. J. Biolog. Sci., 14(1):31-46 (2022)

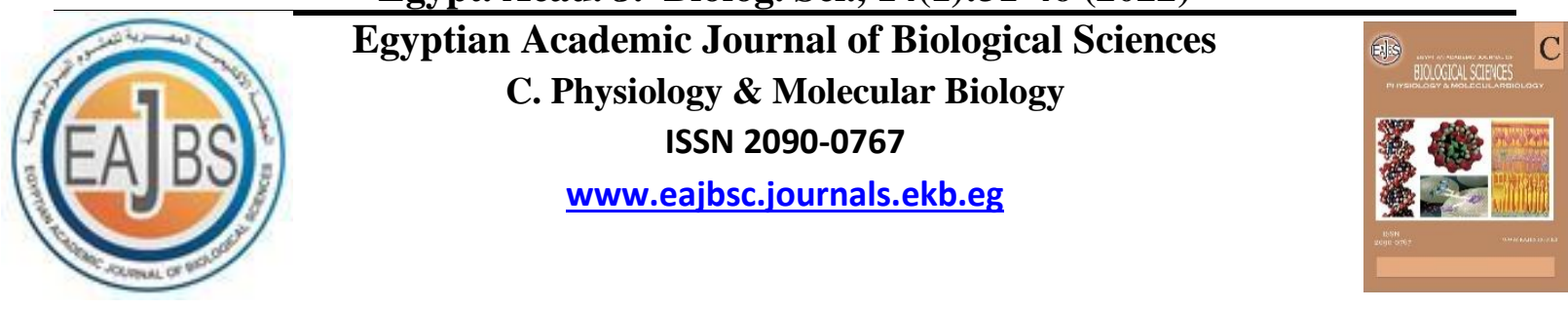

\title{
Magnesium Deficiency Associated with Stress, Systemic Inflammation, and Insulin Resistance in Diabetes Mellitus: a review
}

\author{
Nasr-Eddine Kebir and Touria Zahzeh \\ Laboratory of Molecular Microbiology, Proteomics and Health, Djillali Liabes \\ University of Sidi Bel Abbes, Algeria \\ *E. Mail: higher66@hotmail.fr
}

REVIEW INFO
Review History
Received:27/11/2021
Accepted:12/1/2022
Available:14/1/2022
----------------
Keywords:
Diabetes,
magnesium,
hypomagnesemia,
stress,
inflammation,
insulin resistance.

REVIEW INFO

Accepted:12/1/2022

Available:14/1/2022

Keywords:

Diabetes, magnesium, hypomagnesemia, stress, insulin resistance.

\section{ABSTRACT}

Diabetes mellitus is a metabolic disorder characterized by the presence of chronic hyperglycemia due to lack of insulin secretion, insulin action, or both. It can be immune-mediated (type 1 diabetes) or result from a combination of insulin deficiency and insulin resistance (type 2 diabetes).

Hypomagnesemia has been reported with increased frequency in patients with type 2 diabetes. This electrolyte imbalance is often neglected and subcontracted. Magnesium $(\mathrm{Mg} 2+)$ is an electrolyte of vital physiological importance in the body. It is the most abundant divalent intracellular cation in cells, the second ion after potassium, and the fourth most common cation in the human body. Magnesium is a cofactor in more than 300 enzyme systems that participates in an astonishing array of biochemical reactions in the body, including protein synthesis, muscle and nerve functions, blood glucose control, and blood pressure regulation. Magnesium is also required for energy production, oxidative phosphorylation, and glycolysis.

An adult body contains approximately $25 \mathrm{~g}$ magnesium, with $50 \%$ to $60 \%$ present in the bones and the rest in soft tissues. Less than $1 \%$ of total magnesium is available in the blood serum. In plants, a magnesium ion is at the center of every molecule of chlorophyll, essential for creating energy from sunlight. Magnesium is an essential element for animals and plants, involved in hundreds of enzymatic reactions that affect virtually every aspect of life.

Magnesium deficiency $(\mathrm{MgD})$ is associated with insulin resistance (IR), induces an inflammatory response is strongly associated with stress levels, and an increased risk of type 2 diabetes. Several factors can negatively affect the balance of $\mathrm{Mg} 2+$ in the body and, in the long run, can result in $\mathrm{MgD}$. These factors may be decreased intake of $\mathrm{Mg} 2+$ from food or drinking water, increased loss of $\mathrm{Mg} 2+$ by renal excretion, insufficient absorption of $\mathrm{Mg} 2+$ in the gut, and prolonged use of certain drugs causing hypomagnesemia.

Magnesium supplementation or increased consumption of magnesium-rich foods may be an important tool in the therapeutic management and prevention of type 2 diabetes. In this article, I reviewed the role played by magnesium in the pathogenesis of oxidative stress, systemic inflammation, and insulin resistance. 


\section{INTRODUCTION}

Diabetes mellitus, a lifestyle-related disease that affects $8.3 \%$ of the world's adult population and is growing at an alarming rate, is one of the most prevalent non-communicable diseases due to lifestyle transitions and eating habits (Hameed et al.,2015). Diabetes mellitus (DM) is characterized by chronic hyperglycemia and impaired carbohydrates, lipids, and proteins metabolism caused by complete or partial insufficiency of insulin secretion and/or insulin action (Wu et al., 2014). Unregulated levels of blood glucose can lead to several debilitating conditions such as nephropathy, neuropathy, retinopathy, cardiovascular disease, stroke, and amputations of extremities (Sanjeevi et al.,2018). Minerals that are essential nutrients for the body are inorganic, which makes them resistant to heat. They are involved in various chemical reactions of metabolism and, as enzymatic cofactors, play a key role in various physiological processes. Their deficiency due to increased clearance or ingestion deficit may contribute to secondary complications in some diseases (Granados-Silvestre et al.,2014). Hypomagnesemia in diabetes may contribute to a significant dysregulation of glycemic control and increases the risk of retinopathy, nephropathy, and foot ulcers compared to diabetic patients with normal magnesium (Mg2+) levels (Dasgupta et al.,2012). Magnesium deficiency or the displacement of $\mathrm{Mg} 2+$ by other toxic substances leads to increased genomic instability involved in many diseases and inhibits DNA repair, as well as inflammatory disorders, insulin resistance, hypertension, diabetes mellitus, and cardiovascular diseases (Arigony et $a l ., 2013)$. The UN stated that "...soils constitute the foundation for agricultural development, essential ecosystem functions, and food security and hence are keys to sustaining life on Earth" (Gomiero, 2016). Agricultural policies and projects have traditionally focused only on increasing yields, productivity, and overall food availability in countries or regions, in both developing and developed countries. "Farming systems have never been explicitly designed to promote human health, but focus primarily on increased profitability for farmers and food industries" (Burchi et al., 2011). The nature of modern agricultural practice affects the structure, chemistry, and ecology of the soil in a way that could affect the availability of minerals for plants and thus the mineral content of crops, which means that less and less these essential trace elements are making their way in the food we eat (Mayer,1997). This decrease in the nutrient content of our soils, due to unsustainable agricultural practices, leads to the inevitable loss of the nutritional value of our food (Davey et al., 2013; Gomiero, 2016). Chemical fertilizers and exhausted soils prevent us from getting the magnesium we need (Guo et al., 2016). The scarcity of nutrients in the world is likely to occur sooner than expected. These shortages will affect crop yields, livestock, and public health (Helias et al., 2012). Minerals are a class of nutrients that are essential for maintaining a healthy body. They play a multitude of functional roles in human cells both physiologically and biochemically. Several essential metals are necessary for the proper functioning of many enzymes, transcription factors, and important proteins in various biochemical pathways. Zinc (Zn), Magnesium (Mg2+), and Manganese (Mn) are cofactors for hundreds of enzymes, and $\mathrm{Zn}$ is involved in the synthesis and secretion of insulin from pancreatic beta-cells. (Khan and Awan, 2014). Micronutrient deficiencies, affecting at least 2 billion people, are the cause of "hidden hunger" (Stein and Qaim, 2007). Lifestyle changes in developed countries promote the growth of overweight and obesity, resulting in several metabolic abnormalities (lipids, 
glucose, and blood pressure) and increasing the future risk of type 2 diabetes, cardiovascular events diabetes, and death (de la Sierra, 2009). For these reasons, there is growing interest in the role of micronutrients (trace elements and essential vitamins) in optimizing health and in preventing or treating disease (Shenkin, 2006). However, recent studies have shown, surprisingly, that the $\mathrm{Mg} 2+$ content in historic grain seeds has significantly decreased over time, and that two-thirds of respondents in developed countries received less than their minimum daily requirement in $\mathrm{Mg} 2+$ (Guo et al.,2016). Magnesium is attracting growing interest in physiology, nutrition, and clinical medicine (Saris et al.,2000). This pivotal mineral is needed for a wide variety of physiological functions and biochemical reactions (Dickerman and Liu, 2011). Only ionized magnesium is physiologically active (Pisani et al.,2016). The required daily intake for magnesium in adults is 310 to $420 \mathrm{mg}$. However, Magnesium intake is often lower than these recommendations, especially in the elderly (Volpe, 2013). The hydrosphere (ie oceans and rivers) is, however, the most abundant source of biologically available magnesium. At sea, the concentration of magnesium is about $55 \mathrm{mmol} / \mathrm{L}$ and in the Dead Sea, as an extreme example, it would be $198 \mathrm{mmol} \mathrm{/} \mathrm{L} \mathrm{(Gröber} \mathrm{et}$ al.,2017; Gröber et al., 2015). Several studies have indicated that the deficiency and effectiveness of some key trace metals may play a role in islet function and the development of diabetes mellitus (Wen et al.,2009).

\section{Magnesium:}

The importance of magnesium and its link with the origin of life has been explained since the composition of the earth's crust (rich in iron and magnesium silicate) and the primitive ocean rich in magnesium until the formation of chlorophyll (central molecule) until incorporated into the animal cell (Fawcett et al.,1999). The central role of magnesium in the chlorophyll molecule and as a co-factor for enzymes in the 12 transphosphorylation reactions in photosynthesis probably makes it the most important inorganic element in the production of fossil fuels and food (Mohamed et al.,2012). Magnesium is the eighth root in point of abundance on Earth and constitutes more than $2 \%$ of the total mass of the planet (Smolik et al.,2015). Magnesium plays an important role in plants and animals. In plants, magnesium is the central ion of chlorophyll (Magnesium affects directly or indirectly almost all biochemical and physiological processes occurring within the plant during its course of life, the divalent $\mathrm{Mg} 2+$ cation activates directly 350 enzymes and is and is indirectly involved in thousands of processes in the human body). In invertebrates, magnesium is the fourth most abundant cation (Grzebisz, 2011), and the most abundant ions present in living cells. It is divided into three main compartments of the body: about $65 \%$ in the skeletal mineral phase, about $34 \%$ in the intracellular space, and only $1 \%$ in the extracellular fluid. Magnesium levels in the plasma of healthy people are remarkably constant, averaging 0.85 $\mathrm{mmol} / \mathrm{l}$ and ranging less than $15 \%$ from this value. The distribution of normal values for serum and plasma magnesium is similar in both men and women, and nearly a third is related to plasma proteins. The remaining two-thirds, which are diffusible or ionized, appear to be the biologically active component (Paolisso and Barbagallo, 1997; Paolisso et al.,1990). Total body magnesium in the average adult is about $1000 \mathrm{mmol}$ or $24 \mathrm{~g}$, or $20 \mathrm{mmol} / \mathrm{kg}$ lean mass, while muscles and other soft tissues store between 40 and $50 \%$. About one-third of the bone magnesium content is available for exchange to maintain extracellular 
magnesium levels. Less than $2 \%$ of the magnesium in the body is available in serum and red blood cells, which explains the extracellular magnesium in the body (Abdullah et al.,2018). Extracellular magnesium accounts for only $1 \%$ of total body magnesium, which is found mainly in serum and red blood cells (Kielstein and David. 2013). Serum magnesium, like calcium, can be divided into three fractions. It is either free/ionized, bound to a protein, or complexed with anions such as phosphate, bicarbonate, and citrate or sulfate of the three plasma fractions (Fig. 1) [Jahnen-Dechent and Ketteler, 2012), only ionized magnesium is physiologically active (Sohrevardi et al.,2004).

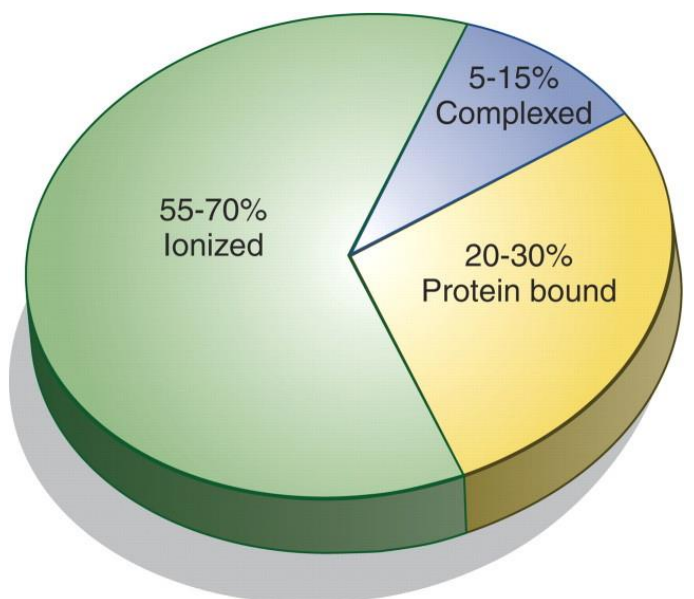

Fig.1. Total serum magnesium is present in three different states because of different measurement methods, results published for each state of serum magnesium vary considerably.

Measuring total magnesium in serum is a convenient and affordable way to monitor changes in the state of magnesium, but it does not necessarily reflect the body's total magnesium content (Razzaque, 2018). $\mathrm{Mg} 2+$ depletion can be seen with normal total serum $\mathrm{Mg} 2+$ concentration (Solati et al.,2014). This measure is a poor predictor of intracellular magnesium content. Nevertheless, most information comes from the determination of $\mathrm{Mg}$ in serum and red blood cells (Felsenfeld et al.,2015). As a cofactor in many enzymatic reactions, magnesium performs a variety of intracellular physiological functions, including energy production, synthesis of DNA and proteins, and participates in the regulation of ion channels (Vormann, 2016; Wolf and Trapani; 2008), and mitochondrial function and is an important factor in cellular and humoral immune responses and mitochondrial function and is an important factor in cellular and humoral immune responses (Kundu et al.,2013). In addition, magnesium is essential for the regulation of muscle contraction, blood pressure, insulin metabolism, cardiac excitability, vasomotor tone, nerve transmission, and neuromuscular conduction [(Pilchova et al., 2017). Over 3751 magnesium binding sites on human proteins have been reported, indicating that its role in human health and disease may have been vastly underestimated (Piovesan et al.,2012). Magnesium is a vital nutrient responsible for over 300 biochemical reactions in the body responsible for:

1. Creation of ATP (Adenosine Triphosphate): Creating energy in the body by activating adenosine triphosphate (ATP).

2. Proper formation of bones and teeth.

3. Relaxation of blood vessels.

4. Action of your heart muscle. 
5. Promotion of proper bowel function.

6. Regulation of glycemia.

7. Acting as a precursor for neurotransmitters like serotonin.

8. Activating muscles and nerves.

9. Helping digest proteins, carbohydrates, and fats.

10. Serving as a building block for RNA and DNA synthesis (Morales-Borges, 2017; Schwalfenbergand Genuis, 2017).

Until recently, the function of magnesium in biological processes was largely ignored to the point of being described as the "forgotten" ion. In recent years, the physiological and therapeutic properties of this essential element have generated renewed interest (Chetan et al., 2002).

Chronic magnesium deficiency (serum magnesium $<0.75 \mathrm{mmol} / \mathrm{L}$ ) is associated with an increased risk of many preclinical and clinical outcomes, including atherosclerosis, hypertension, cardiac arrhythmias, dysfunction lipid metabolism, resistance insulin, metabolic syndrome, type 2 diabetes mellitus, osteoporosis as well as depression and other neuropsychiatric disorders. In addition, magnesium deficiency may be at least one of the pathophysiological links that may help explain the interactions between inflammation and oxidative stress with the aging process and many agerelated diseases (Kostov, K., \& Halacheva, 2018). Insufficient levels of cellular magnesium open the door to deterioration in the proper metabolic function, which usually results in a snowball leading to more serious health problems (Fapohunda, 2018). A deficiency of cellular magnesium can alter the activity of the membranebound sodium-potassium ATPase involved in maintaining sodium, potassium, and glucose transport gradients. It has been suggested that hypomagnesemia could result in a change in cellular glucose transport, a reduction in pancreatic insulin secretion, a defective post-receptor insulin signaling, and/or a change in insulinreceptor interactions with insulin (Kundu et al.,2013).

\section{Magnesium Deficiency:}

Magnesium has received considerable attention for its potential role in improving insulin sensitivity and in preventing diabetes and its cardiovascular complications. It is claimed that $\mathrm{Mg} 2+$ deficiency is common in diabetic patients and that there is an inverse relationship between $\mathrm{Mg} 2+$ consumption and the incidence of type 1 (T1) and type 2 (T2) Diabetes mellitus (DM). A negative correlation between serum $\mathrm{Mg} 2+$ and glycosylated hemoglobin (HbA1c) levels were noted (Saeed et al, 2018; Arpaci et al., 2015). Clinical studies show that T2DM patients with hypomagnesemia have reduced pancreatic $\beta$-cell activity and are more resistant to insulin. In addition, supplementation with dietary $\mathrm{Mg} 2+$ in patients with T2DM improves glucose metabolism and insulin sensitivity (Lisanne et al., 2016). Among the endocrine and metabolic disorders associated with magnesium deficiency, DM is the most common (Shahbah et al., 2017). Primary magnesium deficiency stems from two etiological mechanisms: magnesium deficiency and magnesium depletion. Many factors can cause a decrease in magnesium, such as kidney failure, alcohol consumption, and malabsorption problems (magnesium is absorbed in the small intestines and in the colon, so patients with intestinal or colon lesions such as Crohn's disease, irritable bowel syndrome, celiac disease, gastroenteritis, idiopathic steatorrhea, ulcerative colitis, small bowel resection, ileostomy patients or ulcerative colitis may present a deficiency in magnesium) (DiNicolantonio et al., 2018). Magnesium depletion may be due to dysregulation of factors controlling magnesium status: intestinal hypo-absorption of magnesium, reduced uptake and mobilization of bone 
magnesium, sometimes urinary leakage, hyperadrenoglucocorticism by decreased adaptability to stress, insulin resistance, and adrenergic hyporeactivity ) (Laires et al., 2014; Swaminathan, 2003; Martin et al., 2009).

Magnesium deficiency is due to insufficient intake or decreased levels in many processed foods. The cooking and boiling of the products lead to a significant decrease in the $\mathrm{Mg} 2+$ content of food (Kurstjens et al., 2017). Some commonly used fertilizers and pesticides tend to reduce the $\mathrm{Mg} 2+$ content in the soil and some crops. For example, refined oils, grains, and sugar lose most of their magnesium during processing. In addition, the overuse of pesticides and fertilizers alters the balance of the soil, thereby reducing the content of magnesium and other minerals while growing crops and vegetables. Magnesium absorption is reduced by $30 \%$ with aging. Commonly used medications (for example, certain antibiotics, antacids, and hypertensive medications) decrease the absorption of Mg2+ (Schwalfenberg and Genuis, 2017: Uwitonze and Razzaque, 2018). Therefore, $\mathrm{Mg} 2+$ homeostasis depends on three organs: the intestine, which facilitates the absorption of $\mathrm{Mg} 2+$; bone, the storage system of the body and kidneys, responsible for the excretion of Mg2+ figure2 (Baaij et al., 2012).

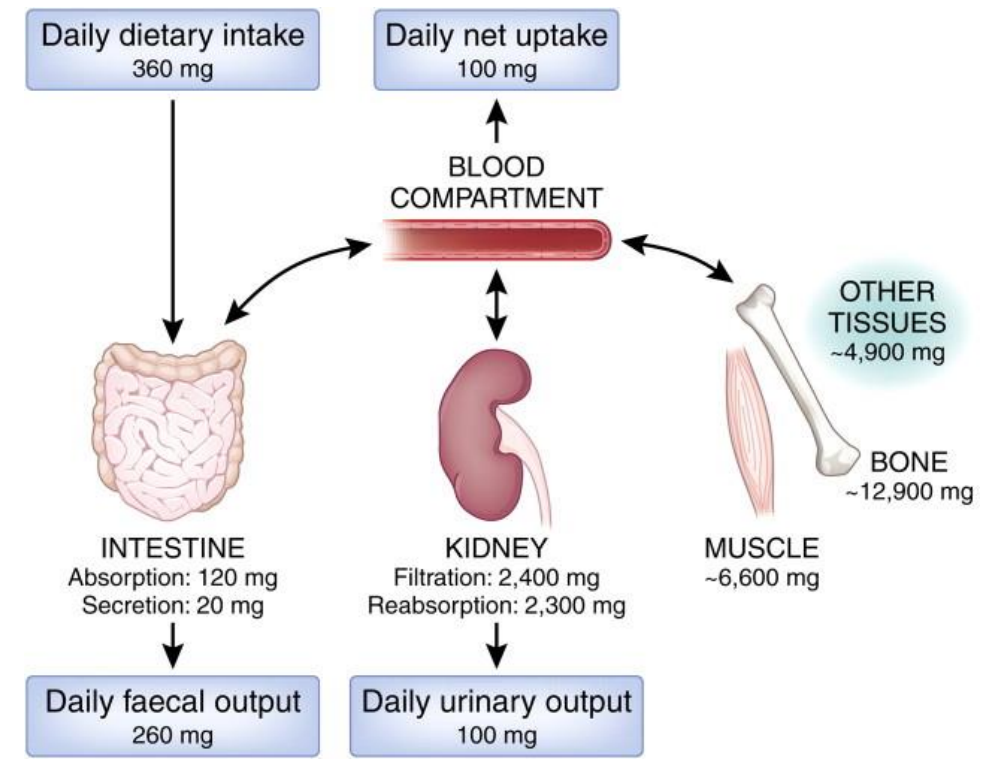

Fig.2. Magnesium homeostasis Panels represent the daily amount of $\mathrm{Mg} 2+$ intake and excretion. A daily net intake of $\sim 100 \mathrm{mg}$ in the intestine results in a balanced 100 $\mathrm{mg}$ excretion in the kidney. In times of $\mathrm{Mg} 2+$ shortage, other tissues such as bone and muscle provide $\mathrm{Mg} 2+$ to restore blood Mg2+ levels. See also "Magnesium basics" in this supplement. The conversion factor from milligrams to millimole is 0.04113 .

\section{Magnesium and Stress:}

The effects of stress on glucose metabolism are mediated by various "counter-regulatory" hormones released in response to stress, which result in high blood glucose and reduced insulin action (Surwit and, Schneider, 1993). Stress is an important contributor to pathological conditions in humans. Hormonal changes in acute and chronic stress can affect glucose homeostasis in healthy people and diabetic patients. Several studies have reported a negative effect of acute stress on the maintenance of blood glucose levels in patients with $\mathrm{T} 1$ and T2 DM (Marcovecchio and Chiarelli, 2012). Magnesium status is strongly associated with stress levels, stress, and 
hypomagnesemia reinforcing the negative effects of each other. Hypomagnesaemia has been associated with stressful conditions such as headaches, fibromyalgia, chronic fatigue syndrome, audiogenic stress, cold stress, and physical stress, among others (Pickering et al., 2020). In turn, low serum magnesium levels increase the release of stress-related hormones, including catecholamines, corticotrophin hormone, and cortisol in response to stress, and affect their access to the brain, creating a vicious circle of reduced resistance to stress and magnesium depletion (Pouteau et al., 2018). A relationship between $\mathrm{Mg} 2+$ status and anxiety is evident in humans. The anxiety of the tests, linked to exposure to stressful examination conditions, is associated with an increase in catecholamines, which is responsible for an increase in urinary magnesium excretion and a decrease in plasma concentrations. Reducing Mg2+ increased anxiety-related behavior in mice (Boyle et al., 2017; Grases et al., 2006)].

Chronic stress reactions are often characterized by long-term activation of the hypothalamic-pituitary-adrenal axis and the sympathetic nervous system, which have been associated with an increased risk of DM (Pouwer et al., 2010). Magnesium has been shown to control hypothalamic-pituitaryadrenocortical (HPA) axis activity, considered the main stress response system (Sartori et al., 2012). Based on the available data, magnesium is a potent inhibitor of the GSK3 enzyme and affects mechanisms/systems that play an important role in the stress response (i.e., limbic-hypothalamus-pituitary-adrenal axis, the release of adrenocorticotropic hormone, benzodiazepine/GABAA receptors) (Serefko et al., 2016).

\section{Magnesium and Inflammation:}

Clinical or experimental studies have shown an association between low- grade inflammation and T2 DM (Oguntibeju, 2019]. Inflammation is an important etiologic factor in the development of insulin resistance and type 2 diabetes, primarily from studies demonstrating the association between high (but "normal") levels of circulating acute inflammatory markers, insulin resistance, and development type $2 \mathrm{DM}$ (Jung et al., 2014). Mg2+ deficiency is a condition that causes changes in the cellular proliferation of the immune system, increases the production of proinflammatory molecules, and influences the onset or aggravation of many diseases (Nielsen, 2014).

Most pathological conditions associated with a low magnesium status have been characterized as having a chronic inflammatory stress component (Nielsen, 2018). Magnesium deficiency results in the release of a pro-inflammatory neuropeptide, and substance $\mathrm{P}$, from neuronal stores, which subsequently results in a cascade of proinflammatory/pro-oxidative events in multiple tissues and organs (Tejero-Taldo et al., 2016). Reduction of dietary magnesium intake and decreased magnesium content in drinking water have been identified as risk factors for the development of hypertension, atherosclerosis, vasospasm, inflammatory conditions, and sudden cardiac death (Long and Romani, 2014).

A recent article discusses the strong link between magnesium supplementation and serum low-density lipoprotein (LDL) cholesterol levels (potentially harmful) and total cholesterol levels. Magnesium would reduce bad cholesterol and increase good cholesterol because it was a powerful antiinflammatory, it would help prevent cholesterol from oxidizing, which could explain its role in reducing atherosclerotic plaque in laboratory animals (Rubaba et al., 2018). 
Various risk factors, including hypertension, diabetes, and smoking, are amplified by the adverse effects of oxidizing LDL cholesterol, triggering a chronic inflammatory reaction, resulting in a vulnerable plaque, prone to rupture, and thrombosis (Willerson and Ridker.,2004).

Diabetic patients, whose magnesium intakes are below the recommended daily allowance RDA, are more likely to have high CRP levels, reflecting higher levels of chronic inflammation related to the extent of their hyperglycemia and insulin resistance (Dibaba et al., 2014; King, 2009). As an acute-phase responsive to low-intensity inflammation, c-reactive protein (CRP) levels have been identified as a significant risk factor for T2 DM, hypertension, and cardiovascular disease (CVD). Therefore, it is plausible that the beneficial effects of magnesium on these chronic diseases are partially mediated by the improvement of the low-grade inflammatory condition (Song et al., 2005). CRP plays a central role in many aspects of atherogenesis, including activation of the complement pathway, lipid capture by macrophages, pro-inflammatory cytokine release, induction of tissue factor formation in monocytes, promotion of endothelial dysfunction, and inhibition of nitric oxide production (King et al., 2005). $\mathrm{Mg} 2+$ dietary intake has been linked to several health effects, including those related to metabolic and inflammatory processes such as hypertension, metabolic syndrome, T2 DM, CVD, osteoporosis, and some cancers like (colonic and breast malignancies). A suggested mechanism for the beneficial effect of $\mathrm{Mg} 2+$ intake is that it could reduce levels of CRP, a deficiency in $\mathrm{Mg} 2+$ that may increase CRP production (Dibaba et al., 2014).

\section{Magnesium and Insulin Resistance:}

Insulin resistance increased tissue inflammation and reactive oxygen species (ROS) production resulting in endothelial dysfunction, increased tissue reninangiotensin-aldosterone system (RAAS), and increased sympathetic nervous system (SNS) activity have all been implicated in this complex pathophysiology of diabetes and hypertension (Govindarajan et al., 2006). Insulin resistance reduces renal reabsorption of $\mathrm{Mg} 2+$, resulting in a loss of $\mathrm{Mg} 2+$ in the urine. As a result, diabetic patients may find themselves in a vicious cycle in which hypomagnesemia increases insulin resistance with resultant hypomagnesemia (Phuong-Chi et al., 2007). Cellular magnesium deficiency is correlated with the altered function of many enzymes using high-energy phosphate bonds, which are involved in glucose metabolism and require magnesium as a cofactor (Pasternak and Horecka, .2010). There is a close relationship between insulin and magnesium where magnesium deficiency is associated with insulin resistance (Chen et al., 2017). An intracellular magnesium deficiency cannot only be a consequence of insulin resistance but can also worsen it (Humphries et al., 1999). Intracellular magnesium plays a key role in regulating insulin action, insulin-induced glucose uptake, and vascular tone. Reduced intracellular $\mathrm{Mg} 2+$ concentrations result in defective tyrosine kinase activity, impaired insulin action, and worsening of insulin resistance in diabetic patients (Barbagallo and Dominguez, 2015). Chronic magnesium deficiency has also been associated with elevated levels of Tumor Necrosis Factor-alpha (TNF-alpha), which may also contribute to post-receptor insulin resistance (GuerreroRomero and Rodriguez-Moran, 2004), thereby establishing a vicious circle that could lead to progressive impairment of metabolic control and increased risk of diabetes complications (Chhabra et al., 2013). Magnesium supplementation improves both the islet beta-cell response and the action of insulin (GuerreroRomero and Rodríguez-Morán, 2011).In addition, it has been reported that, in persons with serum magnesium deficiency, the decrease in insulin 
sensitivity is not adequately compensated by the increase in beta-cell function and that oral magnesium supplementation improves the ability of pancreatic cells to compensate for decreased insulin sensitivity in non-diabetic people with significant hypomagnesemia. These data strongly suggest that magnesium deficiency is also involved in decreasing insulin secretion (Rodríguez-Morán et al., 2012; Milagros et al., 2005). An extensive literature search, shows lower magnesium levels are associated with insulin resistance (Rayssiguier et al., 2006), which is the main pathophysiological cause of T2DM development and many clinical studies have shown a close relationship between hypomagnesemia and insulin resistance in T2DM ((Odusan Olatunde et al., 2017). A large body of evidence shows a link between hypomagnesemia and reduced tyrosine kinase activity at the level of insulin receptors, which may lead to decreased insulin action and the development of insulin receptors, insulin resistance has gradually accumulated in previous years (Rodríguez-Morán and Guerrero-Romero, 2013). Indeed, evidence from experimental studies suggests direct effects of magnesium intake on insulin resistance and T2 DM (Dong et al., 2011). The suppressed intracellular magnesium concentration may result in defective tyrosine kinase activity and modify insulin sensitivity by influencing receptor activity after binding or by influencing intracellular signaling and processing. Intracellular magnesium deficiency may affect the development of insulin resistance and alter the glucose entry into the cell (Takaya et al., 2004). Although recent evidence has suggested that dietary magnesium intake may play an important role in enhancing insulin sensitivity, population-based studies have found conflicting evidence regarding the potential benefit of dietary magnesium intake (Cahill et al., 2013).
Conversely, insulin itself directly stimulates $\mathrm{Mg} 2+$ levels and may contribute to the regulation of $\mathrm{Mg} 2+$ levels (Ligia et al., 1998). Large epidemiological studies indicate that lower serum magnesium levels are associated with insulin resistance (Rayssiguier et al., 2006).

\section{Conclusion:}

Although all evidence from epidemiological studies consistently shows a strong inverse relationship between magnesium status and the risk of type 2 diabetes and its consequences, many physicians are unaware of its importance for the therapeutic management of stress, inflammation, insulin resistance, and glycaemic profiles in diabetic patients. Detection and correction of magnesium status in diabetic patients are clinically appropriate and remain necessary.

Studies have shown that most, but not all, Type 2 diabetes mellitus patients have a magnesium deficiency, hence the need to focus on those with a deficit to correct it. Most studies focus on the total serum magnesium concentration instead of the free, ionized (bioactive) magnesium concentration, which makes it difficult to correlate magnesium deficiency with the disease.

Oral magnesium supplementation and appropriate dietary habits improve insulin sensitivity and metabolic control in patients with Type 2 diabetes mellitus, suggesting that magnesium is an important factor in the etiology and management of diabetes mellitus that is considered a skyrocketing global health pandemic).

\section{Conflicts of Interest}

The authors declare no conflict of interest.

\section{REFERENCES}

Abdullah M. Al Alawi, Sandawana William Majoni, Henrik Falhammar,2018.Magnesium and Human Health: Perspectives and Research Directions". International Journal of 
Endocrinology, vol. 2018, Article ID 9041694, 17 pages, oi.org/ $10.1155 / 2018 / 9041694$.

Alejandro de la Sierra. 2009. Metabolic Syndrome In Hypertension Treatment Challenges And Goals. European Cardiology.Volume 5 Issue 2;5(2):40-43.

Arigony, A. L., de Oliveira, I. M., Machado, M., Bordin, D. L., Bergter, L., Prá, D., \& Henriques, J. A. 2013. The influence of micronutrients in cell culture: a reflection on viability and genomic stability. BioMed research international, 2013, 597282. https://doi.org/10. 1155/ 2013/597282.

Arpaci, D., Tocoglu, A. G., Ergenc, H., Korkmaz, S., Ucar, A., \& Tamer, A. 2015. Associations of serum Magnesium levels with diabetes mellitus and diabetic complications. Hippokratia, 19(2), 153-157..

Barbagallo, M., \& Dominguez, L. J. 2015. Magnesium and type 2 diabetes. World journal of diabetes, 6(10), 1152-1157. https: //doi.org/10.4239/wjd.v6.i10.1152.

Boyle NB, Lawton C, Dye L. 2017. The Effects of Magnesium Supplementation on Subjective Anxiety and Stress-A Systematic Review. Nutrients.9, 429.

Burchi, F., Fanzo, J., \& Frison, E. 2011. The role of food and nutrition system approaches in tackling hidden hunger. International journal of environmental research and public health, 8(2), 358-373. https://doi.org/10.3390/ijerph802 0358.

Cahill F, Shahidi M, Shea J, Wadden D, Gulliver W, Randell E, et al. 2013. High Dietary Magnesium Intake Is Associated with Low Insulin Resistance in the Newfoundland Population. Plos One. 8(3): e58278.

Chen, S., Jin, X., Liu, J. et al. 2017. Association of Plasma Magnesium with Prediabetes and Type 2 Diabetes Mellitus in Adults. Sci Rep 7, 12763 https:// doi.org/10.1038/s4159801713050 $-7$.

Chetan P. Hans, R. Sialy and Devi D. Bansal.2002. Magnesium deficiency and diabetes mellitus. Current Science. Vol. 83, NO. 12, pp 1456- 1463.

Chhabra S, Chhabra S, Ramessur K, Chhabra N. 2013. Hypomagnesemia and its Implications in Type 2 Diabetes Mellitus- A Review Article. WebmedCentral Diabetes, 4(2): WMC004005.

Dana E. King. 2009. Inflammation and elevation of C-reactive protein: does magnesium play a key role?. Magnesium Research. 22 (2): 579.

Dasgupta, A., Sarma, D., \& Saikia, U. K. 2012. Hypomagnesemia in type 2 diabetes mellitus. Indian journal of endocrinology and metabolism, 16(6), 1000-1003. https://doi.org/10.4103/22308210.103020.

Davey L. Jones1, Paul Cross, Paul J. A. et al. 2013. Nutrient stripping : the global disparity between food security and soil nutrient stocks. Journal of Applied Ecology. 50: 851-862.

de Baaij, J. H., Hoenderop, J. G., \& Bindels, R. J. 2012. Regulation of magnesium balance: lessons learned from human genetic disease. Clinical kidney journal, 5(Suppl 1), i15-i24. https: //doi.org/10.1093/ndtplus/sfr164.

Dibaba, D. T., Xun, P., \& He, K. 2014. Dietary magnesium intake is inversely associated with serum C-reactive protein levels: metaanalysis and systematic 
review. European journal of clinical nutrition, 68(4), 510-516. doi:10.1038/ejen.2014.7

Dibaba, D. T., Xun, P., \& He, K. 2014. Dietary magnesium intake is inversely associated with serum C-reactive protein levels: metaanalysis and systematic review. European journal of clinical nutrition, 68(4), 510-516. https://doi.org/10.1038/ejcn.2014. 7.

Dickerman, B., \& Liu, J. 2011. Do the Micronutrients Zinc and Magnesium Play a Role in Adult Depression?. Topics in clinical nutrition, 26(3), 257-267. https:// doi.org/10.1097/TIN.0b013e3182 $260 \mathrm{~d} 86$.

DiNicolantonio, J. J., O'Keefe, J. H., \& Wilson, W. 2018.Subclinical magnesium deficiency: a principal driver of cardiovascular disease and a public health crisis. Open heart. 5:e000668. doi:10.1136/openhrt-2017000668.

Dong, J. Y., Xun, P., He, K., \& Qin, L. Q. 2011. Magnesium intake and risk of type 2 diabetes: meta-analysis of prospective cohort studies. Diabetes care, 34(9), 2116-2122. https://doi.org/10. 2337/dc11-0518.

Fapohunda, O. 2018. Synergistic insulinotropic effect of metformin-Mg2+ adjunct supplement: A case study of streptozotocin-induced type 2 diabetes in sprague dawley rats. Journal of Diabetes, Metabolic Disorders \& Control.5, 38-46.

Fawcett, W.J., Haxby, E.J. and Male, D.A. 1999. Magnesium: Physiology and Pharmacology. British Journal of Anaesthesia. 83, 302320.http://dx.doi.org/10.1093/bja/ 83.2.302.
Federica I. Wolf, Valentina Trapani. 2008. Cell (patho)physiology of magnesium. Clinical Science (Lond) 1114 (1): 27-35. doi.org/ 10.1042/CS20070129

Felsenfeld, A Felsenfeld, A.J., Levine, B.S., \& Rodríguez, M. 2015. Pathophysiology of Calcium, Phosphorus, and Magnesium Dysregulation in Chronic Kidney Disease. Seminars in Dialysis, 28 (6), 564-577.

G. Grases, et al. 2006. Anxiety and stress among science students. Study of calcium and magnesium alterations.Magnesium Research. 19 (2): 102-6.

Gerry K. Schwalfenberg and Stephen J. Genuis. 2017. The Importance of Magnesium in Clinical Healthcare. Scientifica, vol, Article ID 4179326, 14 pages.

Gomiero, Tiziano. 2016. "Soil Degradation, Land Scarcity and Food Security: Reviewing a Complex Challenge.Sustainability . 8, no.3: 281. https://doi.org/10. 3390/su8030281.

Granados-Silvestre, M.D., Ortiz-López, M.G., Montúfar-Robles, I., \& Menjívar-Iraheta, M. 2014. Micronutrients and diabetes, the case of minerals. Cirugia $y$ cirujanos, 82 1, 119-25.

Gröber, U., Schmidt, J., \& Kisters, K. 2015. Magnesium in Prevention and Therapy. Nutrients, 7(9), 8199-8226. https://doi.org/10. 3390/nu7095388.

Gröber, U., Werner, T., Vormann, J., \& Kisters, K. 2017. Myth or Reality-Transdermal Magnesium?. Nutrients, 9(8), 813. https://doi.org/10.3390/nu908081 3.

Grzebisz W. 2011.Magnesium - Food And Human Health. Journal of Elementology. 299-323. DOI: 
10560/jelem.16.2.13

Guerrero-Romero F, Rodríguez-Morán M. 2011. Magnesium improves the beta-cell function to compensate variation of insulin sensitivity: double-blind, randomized clinical trial. European journal of clinical investigation. 41:405-410.

Gurushankar Govindarajan, James R Sowers, Craig S Stump, et al. 2006. Hypertension and Diabetes Mellitus.

European Cardiovascular Disease , 2(1): 21 -4.DOI: https://doi.org/10. 15420/ ecr.2006.1.21 Issue 1;2(1): 1-7.

Hameed, I., Masoodi, S. R., Mir, S. A., Nabi, M., Ghazanfar, K., \& Ganai, B. A. 2015. Type 2 diabetes mellitus: From a metabolic disorder to an inflammatory condition. World journal of diabetes, 6(4), 598-612.

Helias A. Udo de Haes, Roelf L. Voortman, Ton Bastein, A. et al. 2012. Scarcity of micronutrients in soil, feed, food, and mineral reserves - Urgency and policy options Platform Agriculture, Innovation \& Society. p 5.

Humphries, S., Kushner, H.W., \& Falkner, B.E. 1999. Low dietary magnesium is associated with insulin resistance in a sample of young, nondiabetic Black Americans. American journal of hypertension, 128 Pt 1, 747-56.

James T. Willerson and Paul M. Ridker.2004. Inflammation as a Cardiovascular Risk Factor. Circulation.Volume 109, Issue 21 _suppl_1, 1.

Jan T. Kielstein, Sascha David. 2013. Magnesium: the 'earth cure' of AKI?, Nephrology Dialysis Transplantation, Volume 28, Issue 4, April, Pages 785787, https://doi.org/10.1093/ndt/g fs347.

Jung, H. A., Karki, S., Ehom, N. Y., Yoon, M. H., Kim, E. J., \& Choi, J. S.
2014. Anti-Diabetic and AntiInflammatory Effects of Green and Red Kohlrabi Cultivars (Brassica oleracea var. gongylodes). Preventive nutrition and food science, 19(4), 281-290. https://doi.org/10.3746/pnf.2014. 19.4.281.

Kevin J. Martin, Esther A. González and Eduardo Slatopolsky. 2009. Clinical Consequences and Management of Hypomagnesemia Journal of the American Society of Nephrology, 20 (11) 2291-2295; DOI: https://doi.org/10.1681/ASN.

Khan, A. R., \& Awan, F. R. 2014. Metals in the pathogenesis of type 2 diabetes. Journal of diabetes and metabolic disorders, 13(1), 16. https://doi.org/10.1186/22516581-13-16

King, D.E., Mainous, A.G., Geesey, M.E., \& Woolson, R.F. 2005. Dietary Magnesium and C-reactive Protein Levels. Journal of the American College of Nutrition, 24, $166-171$.

Kostov, K., \& Halacheva, L. 2018. Role of Magnesium Deficiency in Promoting Atherosclerosis, Endothelial Dysfunction, and Arterial Stiffening as Risk Factors for Hypertension. International journal of molecular sciences, 19(6), 1724. https://doi. org/10.3390/ijms19061724.

Kundu, D., Osta, M., Mandal, T., Bandyopadhyay, U., Ray, D., \& Gautam, D. 2013. Serum magnesium levels in patients with diabetic retinopathy. Journal of natural science, biology, and medicine, 4(1), 113-116. https:// doi.org/10.4103/0976-9668. 107270.

Kundu, D., Osta, M., Mandal, T., Bandyopadhyay, U., Ray, D., \& Gautam, D. 2013. Serum magnesium levels in patients with 
diabetic retinopathy. Journal of natural science, biology, and medicine, 4(1), 113-116. https:// doi.org/10.4103/09769668.107270.

Ligia J. Dominguez, Mario Barbagallo, James R. Sowers, Lawrence M. Resnick. 1998 Magnesium Responsiveness to Insulin and Insulin-Like Growth Factor I in Erythrocytes from Normotensive and Hypertensive Subjects. The Journal of Clinical Endocrinology \& Metabolism, Volume 83, Issue 12, 1 Pages 4402-4407.

Lisanne M.M. Gommers, Joost G.J. Hoenderop, René J.M. Bindels, Jeroen H.F. de Baaij. 2016. Hypomagnesemia in Type 2 Diabetes: A Vicious Circle?. Diabetes. 65 (1): 3-13. https://doi.org/10.2337/db151028.

Long, S., \& Romani, A. M. 2014. Role of Cellular Magnesium in Human Diseases. Austin journal of nutrition and food sciences, 2(10), 1051.

Marcovecchio ML, Chiarelli F. 2012. The effects of acute and chronic stress on diabetes control. Science Signaling, VOL. 5, NO. 247:pt10.

Maria Isabel Tejero-Taldo, Jay Harlan Kramer, Iu Tong Mak et al.2006.The nerve-heart connection in the pro-oxidant response to $\mathrm{Mg}$-deficiency.Heart Failure Reviews, 11:35-44.

Maria José Laires, Cristina Paula Monteiro and Manuel Bicho. 2004. Role Of Cellular Magnesium In Health And Human Disease. Frontiers in Bioscience, 9, 262-276.

Martha Rodríguez-Morán, Fernando Guerrero-Romero. 2004. Elevated concentrations of TNF-alpha are related to low serum magnesium levels in obese subjects. Magnesium Research, 17(3):18996.

Martha Rodríguez-Morán, MD, MSC and Fernando Guerrero-Romero . 2013.Oral Magnesium Supplementation Improves Insulin Sensitivity and Metabolic Control in Type 2 Diabetic Subjects A randomized doubleblind controlled trial. Diabetes Care, 26(4): 1147-1152.

Mayer, A. 1997, "Historical changes in the mineral content of fruits and vegetables", British Food Journal, Vol. 99 No. 6, pp. 207-211. https: //doi.org/10.1108/0007070971018 1540

Milagros G. Huerta, James N. Roemmich, et al.2005. Magnesium Deficiency Is Associated With Insulin Resistance in Obese Children. Diabetes Care. 28 (5): 1175-1181. https://doi.org/10. 2337/diacare.28.5.1175.

Mohamed A. Hammouda, Hisham S. Khedr, Mohamed A. Alrabiey, Ahmed M. AbdEl-Hamid \& Ahmed M. AbdElAzim. 2012. Effect of magnesium on rotational thromboelastometry (ROTEM) and total blood products requirement in patients undergoing liver transplantation. Egyptian Journal of Anaesthesia, 28:2, 101105, DOI: 10.1016/j.egja.2011.12.006.

Morales-Borges RH. 2017.Magnesium: Important Role in Medicine \& Oncology. Journal of Clinical Trials \& Patenting .2(1): 3.

Nielsen F. H. 2018 Magnesium deficiency and increased inflammation: current perspectives. Journal of inflammation research, 11, 25-34.

Nielsen FH. 2014 Effects of magnesium depletion on inflammation in chronic disease.Current Opinion 
Inclinical Nutrition\& Metabolic Care. 17(6):525-30.

Odusan Olatunde O, Familoni Oluranti Babatope, Odewabi Adesina $\mathrm{O}$ et al. 2017. Patterns and correlates of serum magnesium levels in subsets of type 2 diabetes mellitus patients in Nigeria. Indian journal of endocrinology and metabolism, Volume: 21,Issue Number: 3 Page: 439-442.

Oguntibeju O. O. 2019. Type 2 diabetes mellitus, oxidative stress and inflammation: examining the links. International journal of physiology, pathophysiology and pharmacology, 11(3), 45-63..

Paolisso G, Barbagallo. 1997. M. Hypertension, Diabetes Mellitus, and Insulin Resistance: The Role of Intracellular Magnesium . American Journal of Hypertension.; Volume 10, Issue 3, 1 Page 346-355.

Paolisso, G., Scheen, A., D'Onofrio, F. et al. 1990. Magnesium and glucose homeostasis. Diabetologia. 33:511-514.

Pasternak,K. Kocot,j.Horecka, A.2010. Biochemistry of magnesium. Journal of elementology. 15(3): 601-616.

Phuong-Chi T. Pham, Phuong-Mai T. Pham, Son V. Pham, Jeffrey M. Miller, Phuong-Thu T.2007. Hypomagnesemia in Patients with Type 2 Diabetes.Clinical Journal of the American Society of Nephrology, 2: 366 -373. doi: 10.2215/CJN.02960906

Pickering, Gisèle, André Mazur, Marion Trousselard, Przemyslaw Bienkowski, Natalia Yaltsewa, Mohamed Amessou, Lionel Noah, and Etienne Pouteau. 2020. "Magnesium Status and Stress: The Vicious Circle Concept Revisited" Nutrients, 12, no. 12: 3672. https://doi.org/10.3390/ nu12123672..
Pilchova, Ivana et al.2017. "The Involvement of $\mathrm{Mg}^{2+}$ in Regulation of Cellular and Mitochondrial Functions. Oxidative medicine and cellular longevity vol.(2017): 6797460. doi:10.1155/2017/6797460.

Piovesan, D., Profiti, G., Martelli, P.L. et al. 2012. The human magnesome, detecting magnesium binding sites on human proteins. BMC Bioinformatics, 13, S10 https:// doi.org/10.1186/1471-2105-13S14-S10

Pisani LF, Filippi E, Vavassori S, Munizio N, Vecchi M, Pastorelli L.2016. Effect of proton pump inhibitors on magnesium balance: is there a link to cardiovascular risk? Magnesium research, 29(1): 1-10 doi:10.1684/mrh.2016.0397.

Pouteau, E., Kabir-Ahmadi, M., Noah, L., Mazur, A., Dye, L., Hellhammer, J., Pickering, G., \& Dubray, C. 2018. Superiority of magnesium and vitamin $\mathrm{B} 6$ over magnesium alone on severe stress in healthy adults with low magnesemia: A randomized, single-blind clinical trial. PloS one, 13(12), e0208454. https://doi.org/10.1371/journal.po ne.0208454.

Pouwer, F., Kupper, N., \& Adriaanse, M. C. 2010. Does emotional stress cause type 2 diabetes mellitus? A review from the European Depression in Diabetes (EDID) Research Consortium. Discovery Medicine, 9(45), 112-118.

Rayssiguier Y. , Gueux E , Nowacki W ,. Rock E , Mazur.A.2006.High fructose consumption combined with low dietary magnesium intake may increase the incidence of the metabolic syndrome by inducing inflammation. Magnesium Research. 19 (4): 237-43.

Razzaque M. S. 2018. Magnesium: Are $\mathrm{We}$

Consuming 
Enough? . Nutrients, 10(12), 1863. https://doi.org/10.3390/nu101218 63.

Rodríguez-Morán M, Simental Mendía LE, Zambrano Galván G, GuerreroRomero F. 2012. The role of magnesium in type 2 diabetes: A brief based-clinical review. Magnesium Research, 24(4): 15662.

Rubaba K, Tanjina I, Shafiul I K, Sultana J, Masum B, Ashfia F K,et.al. 2018. Effect of Dietary Magnesium and Calcium on Reducing the Risk of Atherosclerosis in High-Fat Diet Fed Rats. Open Access Journal of Toxicology, 3(3): 555613.

S.M. Sohrevardi, M. Mojtahedzadeh,et al. 2004.Role Of Magnesium Loading Test In Detecting Hypomagnesemia In Critically Ill Patients. Medical Journal of the Islamic Republic of Iran, Volume 18 Number 1. page 35-38.

Saeed, H., Haj, S., \& Qasim, B. 2018. Estimation of magnesium level in type 2 diabetes mellitus and its correlation with HbA1c level. Endocrinology, diabetes \& metabolism. 2(1), e00048. https:// doi.org/10.1002/edm2.48.

Sanjeevi, N., Freeland-Graves, J., Beretvas, S. N., \& Sachdev, P. K. 2018. Trace element status in type 2 diabetes:A meta analysis.Journal of clinical and diagnostic research : JCDR, 12(5), OE01OE08. https://doi.org/10. 7860/ JCDR/2018/35026.11541

Saris NE, Mervaala E, Karppanen H, Khawaja JA, Lewenstam A. 2000. Magnesium An update on physiological, clinical and analytical aspects. Clinica Chimica Acta, Volume 294, Issues 1-2,pp1-26.

Sartori, S. B., Whittle, N., Hetzenauer, A., \& Singewald, N. 2012.
Magnesium deficiency induces anxiety and HPA axis dysregulation: modulation by therapeutic drug treatment. Neuropharmacology. 62(1), 304-312. https://doi.org/ 10.1016/j.neuropharm.2011.07.02 7.

Schwalfenberg, G. K., \& Genuis, S. J. 2017. The Importance of Magnesium in Clinical Healthcare. Scientifica, 2017, 4179326. https://doi.org/10. 1155/ 2017/4179326.

Serefko A, Szopa A, Poleszak E. 2016. Magnesium and depression. Magnesium Research, 29(3): 1129.

Shahbah, Doaaa et al. 2017.“Oral magnesium supplementation improves glycemic control and lipid profile in children with type 1 diabetes and hypomagnesaemia." Medicine vol. 96,11 : e6352. doi:10.1097/ MD.0000000000006352.Oral magnesium supplementation improves glycemic control and lipid profile in children with type 1 diabetes and hypomagnesaemia. Medicine. 2017; 96:11.doi: 10.1097/MD.0000000000006352

Shenkin A. 2006. Micronutrients in health and disease. Postgraduate medical journal,82(971), 559567. https://doi.org/10.1136/ pgmj.2006.047670.

Smolik, J., Mazurkiewicz, A. Kacprzynska-Gołacka J. Et Al.2015 . Composite Layers "Mgal Intermetalic Layer / Pvd Coating" Obtained On The Az91d Magnesium Alloy By Different Hybrid Surface Treatment Methods. Archives of metallurgy and materials, Volume 60 Issue 2 P 1032-1035. .Doi: 10.1515/ Amm-2015-0255 
Solati, M., Ouspid, E., Hosseini, S., Soltani, N., Keshavarz, M., \& Dehghani, M. 2014. Oral magnesium supplementation in type II diabetic patients. Medical journal of the Islamic Republic of Iran, 28, 67.

Steef Kurstjens , Jeroen H F de Baaij , Hacene Bouras et al. 2017. Determinants of hypomagnesemia in patients with type 2 diabetes mellitus. European Journal of Endocrinology, Volume 176: Issue 1, 11-19.

Stein A. J and Qaim M. 2007. The human and economic cost of hidden hunger . Food and Nutrition. Bulletin. 28(2):125-34. doi: 10. 1177/156482650702800201.

Surwit RS, Schneider MS. 1993. Role of stress in the etiology and treatment of diabetes mellitus. Psychosomatic Medicine.; 55(4):380-93. doi.org/10.1097/ 00006842-199307000-00005

Swaminathan R. 2003. Magnesium metabolism and its disorders. The clinical Biochemist Reviews. 24(2):47-66.

Takaya J, Higashino H, Kobayashi Y.2004. Intracellular magnesium and insulin resistance. Magnesium Research, 17(2):126-36.

Uwitonze AM, Razzaque. MS. 2018. Role of Magnesium in Vitamin D Activation and Function. The Journal of the American Osteopathic Association, 118(3): 181-189.

Volpe, S.L. 2013. Magnesium in disease prevention and overall health. Advances in nutrition, 43 , 378S-83S .

Vormann J. 2016. Magnesium: Nutrition and Homoeostasis. AIMS public health, 3(2), 329-340. https://doi. org/10.3934/publichealth.2016.2. 329.
Wanli Guo, Hussain Nazimc, Zongsuo Liang , Dongfeng Yang.2016. Magnesium deficiency in plants: An urgent problem. The Crop Journal.; 4, 83 - 91 .

Wanli Guo, HussainNazim, ZongsuoLiang, DongfengYang. 2016. Magnesium deficiency in plants: An urgent problem. The Crop Journal,Volume 4, Issue 2, Page 83-91.

Wilhelm Jahnen-Dechent, Markus Ketteler. 2012. Magnesium basics, Clinical Kidney Journal, Volume 5, Issue Suppl_1, February 2012, Pages i3 i14, https://doi.org/10.1093/ndtpl us/sfr163.

Wu, Y., Ding, Y., Tanaka, Y., \& Zhang,W. 2014. Risk factors contributing to type 2 diabetes and recent advances in the treatment and prevention.International journal of medical sciences, 11(11), 1185 -1200 .

Y. Rayssiguier, E. Gueux , W. Nowacki, E. Rock1 , A. Mazur. 2006. High fructose consumption combined with low dietary magnesium intake may increase the incidence of the metabolic syndrome by inducing inflammation. Magnesium Research,19 (4): 23743.

Ya Wen Chen, Ching Yao Yang, Chun Fa Huang, Dong Zong Hung, Yuk Man Leung \& Shing Hwa Liu. 2009. Heavy metals, islet function and diabetes development, Islets.; 1:3, 169176.

Yiqing Song, Paul M. Ridker, JoAnn E. Manson, et al. 2005.Magnesium Intake, C-Reactive Protein, and the Prevalence of Metabolic Syndrome in Middle-Aged and Older U.S. Women.DiabetesCare, 28(6):1438 -1444 . 